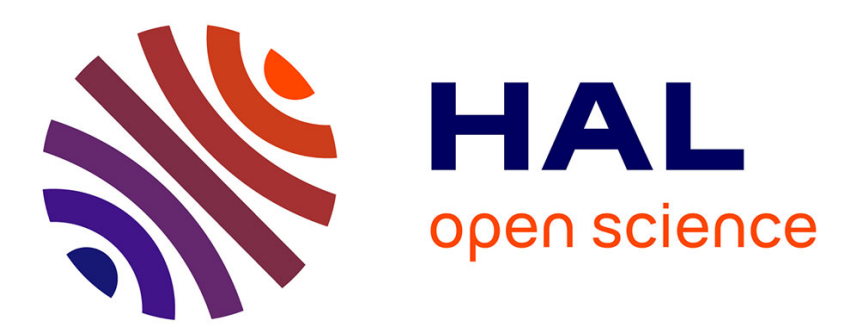

\title{
Nuclear power: What optimal contribution to the French electric power mix?
}

Camille Cany, Christine Mansilla, Gilles Mathonnière, Pascal da Costa

\section{To cite this version:}

Camille Cany, Christine Mansilla, Gilles Mathonnière, Pascal da Costa. Nuclear power: What optimal contribution to the French electric power mix?. International Conference on the European Energy Market, May 2015, Lisbon, Portugal. 10.1109/EEM.2015.7216627 . hal-01264241

\section{HAL Id: hal-01264241 https://hal.science/hal-01264241}

Submitted on 21 Mar 2016

HAL is a multi-disciplinary open access archive for the deposit and dissemination of scientific research documents, whether they are published or not. The documents may come from teaching and research institutions in France or abroad, or from public or private research centers.
L'archive ouverte pluridisciplinaire HAL, est destinée au dépôt et à la diffusion de documents scientifiques de niveau recherche, publiés ou non, émanant des établissements d'enseignement et de recherche français ou étrangers, des laboratoires publics ou privés. 


\section{Nuclear power: what optimal contribution to the French electric power mix?}

\author{
Camille Cany, Christine Mansilla, \\ Gilles Mathonnière \\ Institute for techno-economics of energy systems (I-tésé), \\ Direction de l'Energie Nucléaire \\ Commissariat à l'Energie Atomique et aux Energies \\ Alternatives (CEA) \\ Gif-sur-Yvette, France \\ christine.mansilla@cea.fr
}

\begin{abstract}
In the French context of increasing renewable penetration and significant nuclear power, the optimal contribution of this energy source is discussed from two viewpoints. On the one hand, from the social planner viewpoint, the nuclear optimum contribution is the one that minimizes the overall electric price, whatever the resulting load factor. The use of screening curves, often implemented to design the optimal power mix is questioned, being highly sensitive to the assumptions. On the other hand, from the plant operator viewpoint, the nuclear power plants need to amortize the capital expenses, hence achieve the longest operating time. With a view to make the two viewpoints meet, we propose to operate nuclear power plants as baseloads and consider modulation through the power use, i.e. supply electricity to the electric system when requested and use the remaining power to produce other valuable products, such as heat or hydrogen.
\end{abstract}

Index Terms-- Nuclear Power generation, Power System Economics, Power System Reliability, Renewable Energy Sources

\section{INTRODUCTION}

The general 3X20 European directive proposes renewable penetration goals [1]. In France, $27 \%$ of the electricity is to be produced by renewable resources by 2020 [2] and this share will be continuously growing up to 2050 . In 2013, the share of renewable power already reached $18 \%$ of the domestic production, namely approximately $100 \mathrm{TWh}$ [3].

Among these resources, some are not dispatchable, which triggers challenges to maintain the reliability target level of the power system, both in the short and long term [4], [5]. Wind and solar are expected to contribute to about $10 \%$ of the French electricity production in 2020 [3], [6], and according to voluntaristic scenarios they could contribute to over $50 \%$ of the total electricity production by 2050 [7]. The recent European agreement appears voluntaristic, by announcing a binding target of at least $27 \%$ of renewable energy used at the European level by 2030, and will promote such a development [8].

\author{
Pascal Da Costa, Camille Cany \\ Laboratoire de Génie Industriel / Epocc \\ Ecole Centrale Paris \\ Châtenay-Malabry, France
}

The French power system is currently characterized by a high nuclear penetration: it supplied $82 \%$ of the French domestic consumption and $73 \%$ of the total demand (including exportations) in 2013 [3]. As a matter of fact, nuclear power is meant to remain a significant contributor to the French power system in the medium term, as a low-carbon power source (the current French government projects aim at reducing the nuclear share to $50 \%$ from 2025) [9].

In such a context, one may wonder what would be the optimal contribution of nuclear power to the electric power mix. This paper proposes to provide some insights about this issue.

Two viewpoints are discussed hereafter. On the one hand, from the electric power mix viewpoint, the optimum contribution of nuclear power is the one that minimizes the overall power price for the consumer, whatever the resulting load factor. On the other hand, from the plant operator viewpoint, the nuclear power plants need to amortize the capital expenses, hence achieve the longest operating time. The consequences of these approaches are discussed in what follows and a proposal is done to target making both views meet.

\section{THE ELECTRIC SYSTEM VIEWPOINT}

A. Designing the optimal power mix: The screening curve methodology

The screening curve methodology is a usual methodology to design prospective optimal mix from the social welfare viewpoint. Indeed, the aim is to target the lowest power production cost for the consumer.

This methodology consists in plotting the annual cost of the installed capacity according to the utilization time of the considered technology (cf. Fig. 1). By plotting the curves for each of the available technologies, the optimal annual operating time is obtained for each resource type. On the example given by Fig. 1, nuclear would be operated as a base 
load: it would supply the demand occurring for durations longer than 7900 hours per year. On the contrary, gas would be used for peak demand (durations shorter than 2750 hours per year)

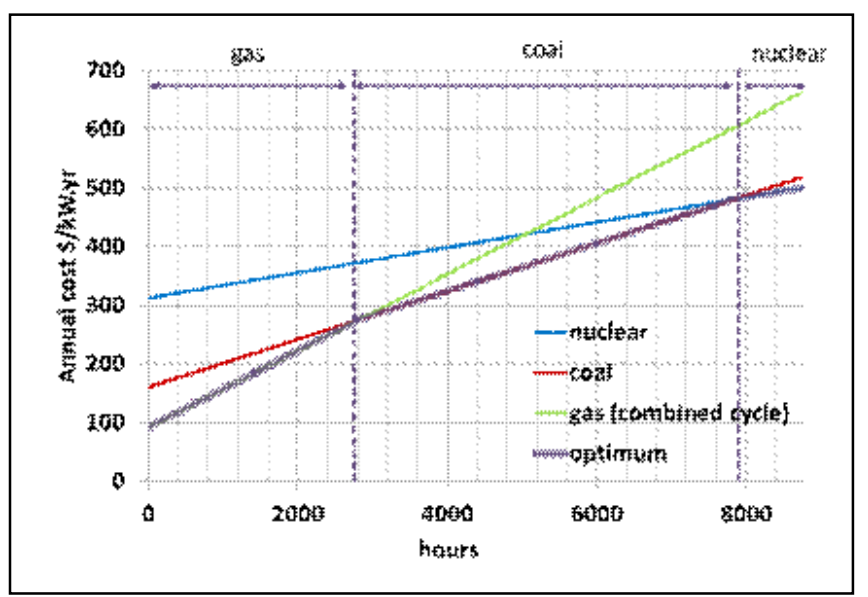

Figure 1. Screening curve example (cost data from [10], 8\% discount rate, no carbon price), own calculus

The second step is to copy the obtained operating time on residual load duration curves, to assess the corresponding optimal installed power, for each power plant type.

A load duration curve represents the sorted hourly load of one year, starting with the highest load hour. The residual load duration curve (cf. Fig. 2) is obtained by withdrawing wind and solar production to the total production on an hourly time step, thus considering that they have a dispatch priority, and then ordering the residual demand from the highest to the lowest value. Besides the screening curves by themselves, residual load duration curves are also used to provide insights about existing power mix management, i.e. how installed capacity operation factor may be affected by the introduction of additional capacity with a dispatch priority.

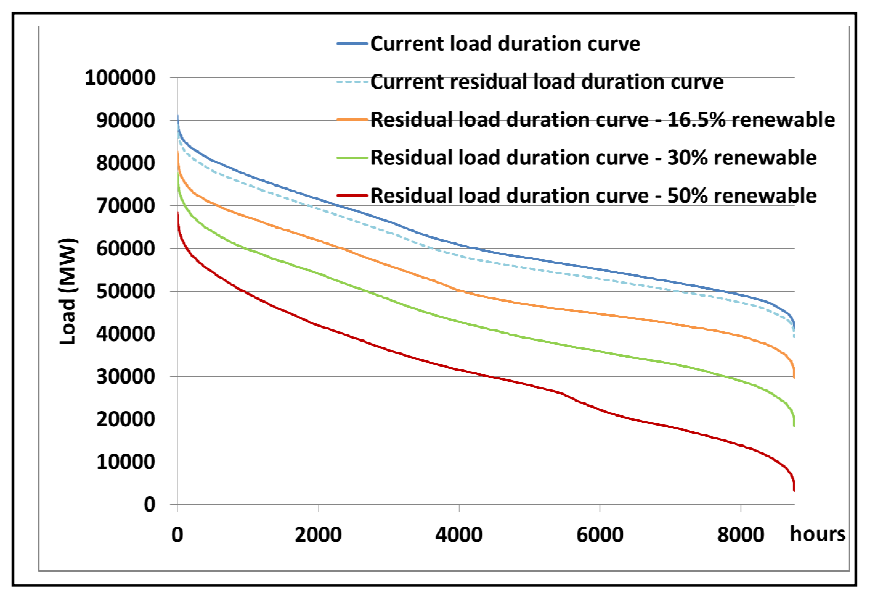

Figure 2. Residual load duration curves, own calculus

Residual load duration curves that were constructed for this study (cf. Fig. 2) are based on historical wind and solar production hourly profiles (between 2010 and 2013), from RTE data (the French Transmission System Operator) [11]. Assuming similar hourly variation shapes, wind and solar production profiles were extrapolated for three renewable penetration rates, as represented in Fig. 2. These rates correspond to scenarios developed by the ANCRE (Alliance Nationale de Coordination de la Recherche pour l'Energie, the French National Alliance for Energy Research Cooperation) for $2030(16.5 \%)$ and $2050(30 \%)$ [6], and by the ADEME (Agence de l'Environnement et de la Maîtrise de l'Energie, the French Environment and Energy Management Agency) for $2050(50 \%)$ [7]. Even if wind and solar penetrations are aggregated in the displayed rates, separate assumptions were considered and the corresponding production profiles were treated separately in the calculations.

It should also be noted that the considered demand, to which wind and solar production are withdrawn, actually includes the exportations. Thus, exportations are assumed exogenous. Additional exportations in case of excess capacities for certain hours may be of interest, if the interconnection capacities allow it.

\section{B. Sensitivity analysis of the optimal mix to the selected assumptions}

Thus, the screening curve methodology seems to be a very straightforward way to design an optimal power mix from the electric system, or social planner, viewpoint. However, we will see in what follows that this method is questionable due to its very high sensitivity to the retained assumptions.

We chose to illustrate this sensitivity through the nuclear share, focus of this paper, and two parameters:

- The discount rate: indeed, this assumption proves critical for very capex-intensive technologies, such as nuclear;

- The carbon price: it is obviously a key parameter to increase the economic competitiveness of low-carbon technologies. As a matter of fact, the European Commission is considering introducing a market stability reserve for Phase 4 of the EU ETS in 2021 [12].

The number of hours for which nuclear becomes the lowest-cost technology compared to coal and gas (e.g. 7900 hours for the case presented in Fig. 1) is provided in Table 1, according to the discount rate and the carbon price assumptions. Cost assumptions were taken from [10].

TABLE I. MINIMUM OPERATING TIME FOR NUCLEAR TO BE THE CHEAPEST TECHNOLOGY

\begin{tabular}{|c|c|c|c|}
\cline { 3 - 4 } \multicolumn{2}{c|}{} & \multicolumn{2}{c|}{ Carbon price } \\
\cline { 3 - 4 } \multicolumn{2}{c|}{} & $\mathbf{\$ 0 / \text { ton } _ { \mathbf { C O } 2 }}$ & $\mathbf{\$ 3 0 / \text { ton } _ { \mathbf { C O } 2 }}$ \\
\hline \multirow{3}{*}{ Discount rate } & $\mathbf{5 \%}$ & $5000 \mathrm{~h}$ & $3000 \mathrm{~h}$ \\
\cline { 2 - 4 } & $\mathbf{8 \%}$ & $8000 \mathrm{~h}$ & $5000 \mathrm{~h}$ \\
\cline { 2 - 4 } & $\mathbf{1 0 \%}$ & $\begin{array}{c}\text { Never } \\
\text { competitive }\end{array}$ & $6000 \mathrm{~h}$ \\
\hline
\end{tabular}


As a result, the nuclear power that would be installed from the electric system viewpoint would be much contrasted according to the retained assumptions. To illustrate this statement, we calculated the sensitivity of the requested nuclear power for the ANCRE scenario for 2030, corresponding to a $16.5 \%$ renewable penetration in France (wind plus solar). The reference case is chosen to be $8 \%$ discount rate and no carbon price. The results are presented in Table 2.

TABLE II. OPTIMAL REQUESTED NUCLEAR POWER (\% VARIATION COMPARED TO REF) FROM THE ELECTRIC SYSTEM VIEWPOINT - $16.5 \%$ WIND AND SOLAR PENETRATION

\begin{tabular}{|c|c|c|c|}
\cline { 3 - 4 } \multicolumn{2}{c|}{} & \multicolumn{2}{c|}{ Carbon price } \\
\cline { 3 - 4 } \multicolumn{2}{c|}{} & $\$ 0 /$ ton $_{\mathrm{CO} 2}$ & $\$ 30 /$ ton $_{\mathrm{CO} 2}$ \\
\hline \multirow{3}{*}{ Discount rate } & $\mathbf{5 \%}$ & $+19 \%$ & $+42 \%$ \\
\cline { 2 - 4 } & $\mathbf{8 \%}$ & Reference & $+19 \%$ \\
\cline { 2 - 4 } & $\mathbf{1 0 \%}$ & $-100 \%$ & $+13 \%$ \\
\hline
\end{tabular}

Besides the high sensitivity of the methodology we presented, this approach limits the nuclear use to supplying power to the electric system. As we will see in section IV, other operating modes may widen the scope.

\section{THE PLANT OPERATOR VIEWPOINT}

The plant operator viewpoint is somewhat different. The operating time is actually a target. The nuclear power plants need to amortize the capital expenses, hence achieve the longest operating time. This statement may appear straightforward, but it is all the more important that nuclear power plants are capex-intensive.

Giving dispatch priority to variable renewable energy results in lowering the operating time of already existing nuclear reactors, in the short term. We assessed this impact according to the nuclear power capacity and the renewable installed capacity, through the use of residual load curves. The renewable penetration assumptions were derived from the scenarios presented in section II.A [6]-[7]. Two nuclear installed capacity values have been considered: $i$ / the installed capacity needed to supply $50 \%$ of the annual electricity production, in line with the French Government policy, and ii/ an in-between value of $65 \%$ (as a compromise between the current contribution of nuclear power in the French electricity mix and the prospective $50 \%$ value). Results in terms of nuclear load factors are presented in Table 3.
TABLE III. RESULTING NUCLEAR LOAD FACTOR ACCORDING TO THE RENEWABLE AND NUCLEAR INSTALLED CAPACITIES IN THE FRENCH ELECTRICITY MIX

\begin{tabular}{|c|c|c|c|}
\cline { 3 - 3 } \multicolumn{2}{c|}{} & \multicolumn{2}{c|}{$\%$ Nuclear } \\
\cline { 3 - 4 } \multicolumn{2}{c|}{} & $\mathbf{5 0}$ & $\mathbf{6 5}$ \\
\hline \multirow{3}{*}{$\%$ Renewable } & $\mathbf{1 6 . 5}$ & $74 \%$ & $70 \%$ \\
\cline { 2 - 4 } & $\mathbf{3 0}$ & $69 \%$ & $61 \%$ \\
\cline { 2 - 4 } & $\mathbf{5 0}$ & $51 \%$ & $43 \%$ \\
\hline
\end{tabular}

By considering the French current unit capability factor: $78 \%$ [13], and the French regulated tariff for nuclear energy: $€ 42 / \mathrm{MWh}$ (i.e. tariff for power suppliers that want to buy nuclear power in order to sell it to consumers; this tariff was implemented in 2010 to smooth the advantage of the historical utility, and make it possible for the other utilities to compete), the annual revenue losses can be estimated. Using the above assumptions, they are calculated as the energy losses (i.e. energy production difference between the resulting load factor from Table III and the unit capability factor), multiplied by the power price. The figures are presented in Table 4. In Table 5, the revenue losses are estimated as a share of the maximum foreseeable revenue, according to the unit capability factor.

TABLE IV. ANNUAL REVENUE LOSSES ACCORDING TO THE RENEWABLE AND NUCLEAR INSTALLED CAPACITIES IN THE FRENCH ELECTRICITY MIX $(\mathrm{M} €)$

\begin{tabular}{|c|c|c|c|}
\cline { 3 - 3 } \multicolumn{2}{c|}{} & \multicolumn{2}{c|}{$\%$ Nuclear } \\
\cline { 3 - 4 } \multicolumn{2}{c|}{} & $\mathbf{5 0}$ & $\mathbf{6 5}$ \\
\hline \multirow{3}{*}{$\%$ Renewable } & $\mathbf{1 6 . 5}$ & 660 & 1550 \\
\cline { 2 - 4 } & $\mathbf{3 0}$ & 1430 & 3390 \\
\cline { 2 - 4 } & $\mathbf{5 0}$ & 4150 & 6960 \\
\hline
\end{tabular}

TABLE V. ANNUAL REVENUE LOSSES ACCORDING TO THE RENEWABLE AND NUCLEAR INSTALLED CAPACITIES IN THE FRENCH ELECTRICITY MIX: SHARE OF THE MAXIMUM FORESEEABLE REVENUE (\%)

\begin{tabular}{|c|c|c|c|}
\cline { 3 - 4 } \multicolumn{2}{c|}{} & \multicolumn{2}{c|}{$\%$ Nuclear } \\
\cline { 3 - 4 } \multicolumn{2}{c|}{} & $\mathbf{5 0}$ & $\mathbf{6 5}$ \\
\hline \multirow{3}{*}{$\%$ Renewable } & $\mathbf{1 6 . 5}$ & 5 & 10 \\
\cline { 2 - 4 } & $\mathbf{3 0}$ & 12 & 22 \\
\cline { 2 - 4 } & $\mathbf{5 0}$ & 34 & 45 \\
\hline
\end{tabular}

These figures highlight that reduced load factors are not economically viable in the long-run.

However, significant renewable power penetration does not necessarily mean reducing the nuclear share. As a matter of fact, to achieve a low-carbon power mix, low-carbon power sources should be complementarily promoted. 
Thus, a possible way would be not reducing the nuclear load factor but finding new outlets. This is what is discussed in next section.

\section{NUCLEAR MODULATION: TOWARDS A VIEWPOINT MERGING}

As a matter of fact, a gap can result from the difference between the installed nuclear capacity and what is considered optimal: either from the electric system viewpoint (with all the attached uncertainties that were pointed out in section II), or from the operator viewpoint, to reach the maximum load factor. Figure 3 provides an illustration.

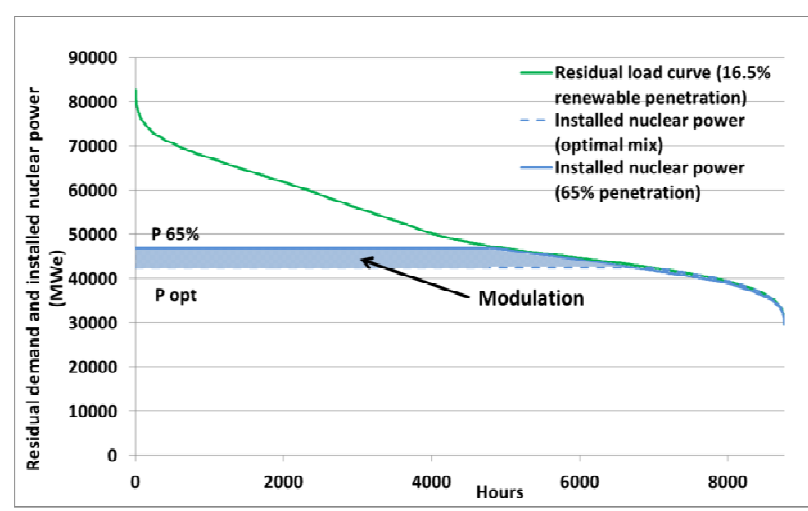

Figure 3. Example of assessment of the nuclear power modulation capacity ( $\mathrm{P}$ opt is assessed to reach a $78 \%$ load factor), own calculus

Nuclear power could participate to system balancing thanks to characteristics compatible with power modulation [15]-[17]. Indeed, nuclear modulation seems to be achievable, especially in the case of France, since a large production variation could be reached only by small increments in each power plant. This would remain true as long as installed nuclear power is large enough, in terms of contribution to the total electricity mix. Further R\&D works are still needed though, to check if implementing higher modulation needs appears technically and economically feasible.

However, instead of charging power modulation, which would mean charging energy losses, it would be worth considering taking advantage from the available energy to produce valuable services and products [18]. Indeed, when the load factor becomes too low, the nuclear economic equation remains unsolved in the case of a new plant to be built. The share of capital is too large to allow an efficient use with such low load factors. The question appears more complex if we examine the case of already existing reactors. This load factor is in the range for which the competitiveness of nuclear begins to decline when facing gas combined cycles and possibly wind power. In fact, the decision of maintaining nuclear power plants with low load factors would be highly linked with payments for grid services (i.e. reduction of system costs). Future research should address this question in details.

Thus, we propose to consider nuclear power modulation through the power use. In this case, the nuclear power plant would be operated as a baseload and electricity would be supplied to the electric system when requested. For the remaining time, instead of reducing the plant load, the output could be used to produce other vectors, such as heat or hydrogen. Hydrogen is also a chemical product that has very numerous outlets: ammonia production, refining activities, synthetic fuel production, and is a means to enhance connections between energy networks (e.g. power and gas, through power-to-gas). Finally, hydrogen also makes it possible to integrate high shares of low-carbon energy into a given mix by avoiding both to reduce baseload power such as nuclear and to curtail non-dispatchable renewable energy [19].

Detailed business models remain to be developed in this field though. Indeed, systems comprising nuclear power plant together with a hydrogen process may propose new energy services such as hydrogen and power supply. What is more, implementing high temperature steam electrolysis (HTSE) process [20] in the longer term can make it possible to supply power as a baseload (thanks to the nuclear plant) and for peak demand (thanks to reversible HTSE operation). During high demand peaks, such a new concept would allow to use the power from the nuclear power plant, but also from the reversible electrolyser (thus acting as an energy storage), doubling the instantaneous power of the nuclear plant. This will be the topic of future works.

By promoting new concepts, potentially more economical, R\&D is needed to improve the business cases. First studies demonstrated that, to reach a low-carbon power mix, both nuclear and renewables are needed, in a stronglyinterconnected energy system perspective [19].

\section{CONCLUSION AND PERSPECTIVES}

In the French current electricity mix which is characterized by a high share of nuclear power, and in the context of current design of energy transition policies, the optimal nuclear share is a central issue.

This paper investigated the screening curve methodology, which is usually implemented to calculate prospective optimal power mixes. We highlighted that defining the optimal nuclear installed capacity following this methodology entails uncertainties. Following the electric system viewpoint, the target is the lowest electricity production cost, not the plant amortization. Thus, it may lead to reduced load factors.

From the operator viewpoint, the capital expenses must be amortized, hence the maximum load factor should be aimed at. We assessed that, according to installed renewable and nuclear power in the mix, significant revenue losses may result from both high penetration rates of renewable and nuclear.

Nevertheless, what should be aimed at is the lowest carbon-content. There should not be harsh competition between low-carbon power sources. On the contrary, complementarities, and even synergies, should be sought for.

Despite the fact that nuclear modulation seems to be achievable, especially in the case of France since a large production variation could be reached only by small increments in each power plant, using the available energy seems more profitable at first sight. Conversely, even if excess renewable energy could be curtailed, taking advantage of the excess power seems more fruitful. 
Thus, we proposed to consider nuclear power use modulation rather than nuclear power production modulation. In this case, available power is converted into valuable services to the electric system and can also be converted into valuable industrial products. In this respect, hydrogen seems especially worthwhile, given its multiple outlets and future specific position within the energy system.

To reach a low-carbon power mix, both nuclear and renewables are needed, in a strongly-interconnected energy system perspective. In such a synergistic power system, both nuclear power plant flexibility and nuclear plant operation time extension should be examined, also by considering novel uses.

New economic tools have to be built to address these important questions. However, first of all, the physical and safety constraints limiting nuclear plants power ramps needs to be investigated. In this paper, it is supposed that a perfect load follow would be achievable. This is yet to be verified and a first task is to improve our knowledge in this field. Works are underway in the research organizations.

\section{ACKNOWLEDGMENT}

This work was carried out in the framework of a $\mathrm{PhD}$ thesis. The authors want to thank J. C. Bocquet, Head of the Laboratoire de Génie Industriel, and J. G. Devezeaux, Head of the Institute for techno-economics of energy systems (I-tésé) for the fruitful discussions.

\section{REFERENCES}

[1] European Directive 2009/28/CE, 23 Apr. 2009.

[2] Ministère de l'Ecologie, de l'Energie, du Développement Durable et de la Mer, "Plan d'action national en faveur des énergies renouvelables. Période 2009-2020. En application de l'article 4 de la Directive 2009/28/CE de l'Union Européenne", 2009.

[3] RTE, "Bilan prévisionnel de l'équilibre offre-demande d'électricité en France - édition 2014", 2014. Available: http://www.rtefrance.com/sites/default/files/bilan_complet_2014.pdf

[4] R. Gross, P. Heptonstall, D. Anderson, T. Green, M. Leach et al., "The costs and impacts of intermittency: an assessment of the evidence on the costs and impacts of intermittent generation on the British electricity network", UK Energy Research Centre, London, UK, Mar. 2006.

[5] E. Hart, E. D. Stoutenburg, and M. Z. Jacobson, "The potential of intermittent renewables to meet electric power demand: current methods and emerging analytical techniques", Proceedings of the IEEE, 100(2), pp. 322-334, Feb. 2012.

[6] ANCRE, "Scénarios de l'ANCRE pour la transition énergétique", 2013.

[7] ADEME, "L'exercice de prospective de l'ADEME: Vision 20302050", Jun. 2013.

[8] European Commission, "Energy and climate goals for 2030", 2014. Available: http://ec.europa.eu/energy/2030_en.htm

[9] Assemblée Nationale, "Projet de loi relatif à la transition énergétique pour la croissance verte", Texte adopté $\mathrm{n}^{\circ} 412$, Session ordinaire de 2014-2015, 14 octobre 2014. Available: http://www.assembleenationale.fr/14/pdf/ta/ta0412.pdf

[10] M. S. Salvadores, J. H. Keppler, "Projected costs of generating electricity", Nuclear Energy Agency, OECD, Paris, France, 2010.

[11] RTE database. [Online]. Available: http://www.rtefrance.com/fr/developpement-durable/eco2mix/telechargement-dedonnees

[12] P. Gregorin, "Reform of the EU emissions trading system", presented at the $3^{\text {rd }}$ European energy forum, Paris, France, 24-25 April 2014.

[13] ELECNUC. Nuclear power plants in the world. 2014 ed.

[14] Ministère de l'Ecologie, du Développement durable et de l'Energie, Regulated access to nuclear power, 4 November 2013. Available: http://www.developpement-durable.gouv.fr/Le-prix-de-l-ARENH.html

[15] C. Bruynooghe, A. Eriksson, and G. Fulli, "Load following operating mode at nuclear power plants and incidence on operation and maintenance costs. Compatibility with wind power variability", EC, JRC Scientific and Technical Reports, Brussels, Belgium, 2010.

[16] A. Lokhov, "Technical and economic aspects of load following with nuclear power plants", NEA, OECD, Paris, France, Jun. 2011.

[17] A. M. Choho, "Major innovation in PWR load follow operations by AREVA", in Proc. 2013 Atoms for the Future Conf.

[18] M. F. Ruth, O. R. Zinaman, M. Antkowiak, R. D. Boardman, R. S. Cherry, and M. D. Bazilian, "Nuclear-renewable hybrid energy systems: opportunities, interconnections and needs", Energy Convers Manage. vol. 78, pp. 684-694, Feb. 2014.

[19] P. Caumon, M. Lopez-Botet Zulueta, J. Louyrette, S. Albou, C. Bourasseau, C. Mansilla, "Flexible hydrogen production implementation in the French power system: expected impacts at the French and European levels", Energy, in Press. Doi: 10.1016/j.energy.2014.12.073

[20] J. Mougin, M. Reytier, S. Di Iorio, A. Chatroux, M. Petitjean, J. Cren, J. Aicart, M. De Saint Jean, "Stack performances in High temperature steam electrolysis and co-electrolysis", in Proc. 2014 World Hydrogen Energy Conf. 